\title{
PENIMBUNAN MATERIAL LUMPUR CAIR DENGAN MENGGUNAKAN METODE SLIDING PAD
}

\author{
Siswo Afrianto ${ }^{1)}$ dan Chairul Nur Azmi ${ }^{2)}$ \\ ${ }^{1)}$ Mine Engineer \& Data Analyst, Sambarata Mining Operation Department, PT Berau Coal \\ ${ }^{2}$ Short Term Mine Plan Engineer Coordinator, Short Term Mine Plan Department, PT Berau Coal
}

\begin{abstract}
ABSTRAK
Material lumpur dalam area penambangan merupakan material khusus yang perlu penanganan tertentu dalam proses pengangkutan dan penimbunannya di area disposal. Pada umumnya, material lumpur dapat dibedakan menjadi dua, yaitu lumpur original atau lumpur rawa yang sudah terbentuk sebelum aktifitas penambangan dilakukan dan lumpur sedimentasi hasil erosi material insitu maupun material di disposal. Lumpur sedimentasi memiliki karakteristik lebih cair dibandingkan dengan lumpur rawa. Hal ini disebabkan karena pada umumnya material lumpur cair terbentuk pada area sump atau titik terendah pit yang tergenang dengan waktu yang cukup lama. Pada proses pengangkutannya, material lumpur cair dapat diangkut menggunakan unit truk dengan menggunakan vessel khusus untuk menjaga agar muatannya tidak tumpah. Material kemudian diangkut menuju area disposal yang sudah dilakukan kajian terkait aspek geoteknik, untuk menjaga kestabilan lereng tetap terjaga. Pada proses penimbunan material lumpur sedimentasi, unit truk tidak diperkenankan melakukan penimbunan bebas di bibir lereng disposal. Hal ini dikarenakan terdapat potensi ketidakstabilan lereng, sehingga diperlukan jarak aman pada saat melakukan penimbunan. Untuk itu, diperlukan sliding pad (landasan luncur) untuk mengalirkan material lumpur dari jarak aman unit truk ke bibir disposal. Hal ini dapat dilakukan dengan memanfaatkan viskositas lumpur cair sedimentasi. Melihat penimbunan material lumpur cair di disposal memerlukan penanganan khusus, maka makalah ini disusun guna menjelaskan metode penimbunan lumpur sedimentasi di area disposal dengan mempertimbangan aspek teknis, produktifitas, serta aspek keselamatan.
\end{abstract}

Kata kunci : lumpur sedimentasi, disposal, penimbunan

\section{ABSTRACT}

Mud material in the mining area is a special material that needs certain handling in the process of transporting and storing it at the disposal area. In general, mud material can be divided into two, namely original mud or swamp mud that has been formed before mining activities are carried out and sedimentation sludge as a result of erosion of internal material and material at disposal. Sedimentation mud has more fluid characteristics compared to swamp mud. This is because in general the sludge material is formed in the sump area or the lowest point of the inundated pit with a considerable amount of time. In the transport process, liquid mud material can be transported using a truck unit using a special vessel to keep the load from spilling. The material is then transported to the disposal area which has been carried out studies related to the Geotechnical aspects, to maintain the stability of the slope to be maintained. In the process of dumping sedimentation mud material, truck units are not permitted to carry out free dump at the crest of the slope. This is because there is a potential for slope instability, so that a safe distance is needed when doing mud dumping. For this reason, a sliding pad is needed to drain the mold material from the truck unit's safe distance to the crest disposal. This can be done by utilizing the viscosity of sedimentary liquid sludge. Seeing the accumulation of liquid mud material at disposal requires special handling, so this paper was prepared 
to explain the method of sedimentation mud accumulation in the disposal area by considering technical aspects, productivity, and safety aspects.

Keywords : sedimentation mud, disposal, dumping

\section{A. PENDAHULUAN}

\section{A.1. Latar Belakang}

Sambarata Mine Operation merupakan salah satu dari empat department di Mining Operation \& Support Division PT Berau Coal, yang berfungsi melakukan aktifitas penambangan dari tahapan pengupasan tanah pucuk sampai dengan pengangkutan batubara ke Coal Processing Plant (CPP) serta pemuatan ke barge. Setiap mine operation department di PT Berau Coal memiliki tantangan-tantangan tersendiri dalam melakukan kegiatan penambangan. Pada area Sambarata Mine Operation, khususnya di Pit C2 terdapat karakteristik batubara berupa sinklin sehingga perlu perencanaan khusus dalam melaksanakan penambangan.

Pada tahun 2017, Pit C2 memiliki target produksi sebesar 21,48 juta bcm untuk overburden dan 2,16 juta mt untuk batubara. Untuk mencapai target produksi tersebut dibutuhkan penambangan di area sinklin batubara dimana pada area tersebut terdapat material lumpur sebesar $500.000 \mathrm{bcm}$ yang harus di angkut. Dalam pengangkutan material lumpur tersebut, dibutuhkan perencanaan yang cukup rinci agar menjaga operasional penambangan dapat berjalan dengan aman dan target produksi dapat tercapai. Perencanaan ini dibuat dari lokasi front loading sampai menuju ke area disposal. Pemilihan metode yang tepat juga dibutuhkan untuk menjaga produktifitas pengangkutan material lumpur.

Material lumpur di area sinklin Pit C2 merupakan material lumpur hasil sedimentasi yang memiliki karakterisik yang cukup encer, sehingga dalam pengangkutannya digunakan unit dump truck dengan vessel khusus yang memiliki penutup pada bagian belakang atau sering disebut sebagai HD Duck Tail. Unit tersebut lebih efektif digunakan untuk pengangkutan material lumpur dikarenakan material yang diangkut dapat sepenuhnya material lumpur cari dan tidak diperlukan material keras di bagian belakang vessel yang berguna menjaga material lumpur tersebut agar tidak tumpah. Material penjaga tersebut umumnya akan menjadi masalah pada operasional pengangkutan material lumpur, seperti ketersediannya di area front loading, cost yang tinggi karena double handling, dan juga perlu maintenance yang rutin di area disposal. Pada area diposal, penimbunan material lumpur cair harus diperhatikan baik secara lokasi maupun teknis penimbunannya. Pada umumnya disposal material lumpur memiliki potensi ketidakstabilan lereng yang cukup tinggi. Untuk itu lokasi disposal lumpur tersebut harus dibuat kajian geoteknik terlebih dahulu untuk mencegah terjadinya insiden yang dikarenakan ketidakstabilan lereng. Selain itu, teknis penimbunan pada disposal lumpur berbeda dengan penimbunan material overburden pada umumnya. Posisi unit dump truck tidak diperkenankan berada pada bibir/crest disposal. Hal ini dilakukan sebagai pengendalian terhadap resiko ketidakstabilan lereng dan terjatuhnya unit dump truck dari crest disposal.

Oleh karena itu dibutuhkan sliding pad atau landasan yang digunakan untuk mengalirkan material lumpur dari unit dump truck menuju void lumpur. Posisi sliding pad tersebut tegak lurus dengan crest disposal, sehingga menghilangkan resiko unit dump truck terjatuh dari crest disposal ke dalam void lumpur. Kemiringan sliding pad juga dapat mengakomodir pergerakan material lumpur dengan gaya gravitasi. Hal ini juga dapat meminimalkan maintenance yang diperlukan di area disposal sehingga mengurangi beban kerja unit dozer. 


\section{A.2. Kondisi Lapangan}

Secara umum disposal IPD C2 dapat dibagi menjadi 3 area yaitu disposal sisi utara, sisi selatan, dan sisi barat. Area sisi utara merupakan area bekas Pit C2 yang telah ditimbun dan mencapai elevasi +90 , pada area ini dasar disposal merupakan void lumpur bekas sump Pit C2 yang besar dimana telah terjadi beberapa retakan akibat bergeraknya material disposal yang disebabkan ketidakseimbangan dalam menentukan staging penimbunan dan ketidaksesuaian dengan desain yang telah ditentukan. Area rencana penimbunan material lumpur berada pada elevasi +60 dan elevasi +90 , dengan karakteristik area berada di atas timbunan yang telah dibentuk.

Pada area elevasi +60 timbunan material lumpur direncanakan pada area cekungan sisi timur IPD C2 dengan batas terdapat bukit di sisi timur area tersebut, sedangkan untuk sisi selatan akan dilakukan penimbunan material overburden sebagai tanggul material lumpur. Mengacu pada desain tahun 2017 IPD C2 area rencana lumpur yang akan ditimbun pada area ini berasal dari material lumpur sedimentasi sinklin seam H Pit C2 dengan volume mencapai $500.000 \mathrm{~m}^{3}$.

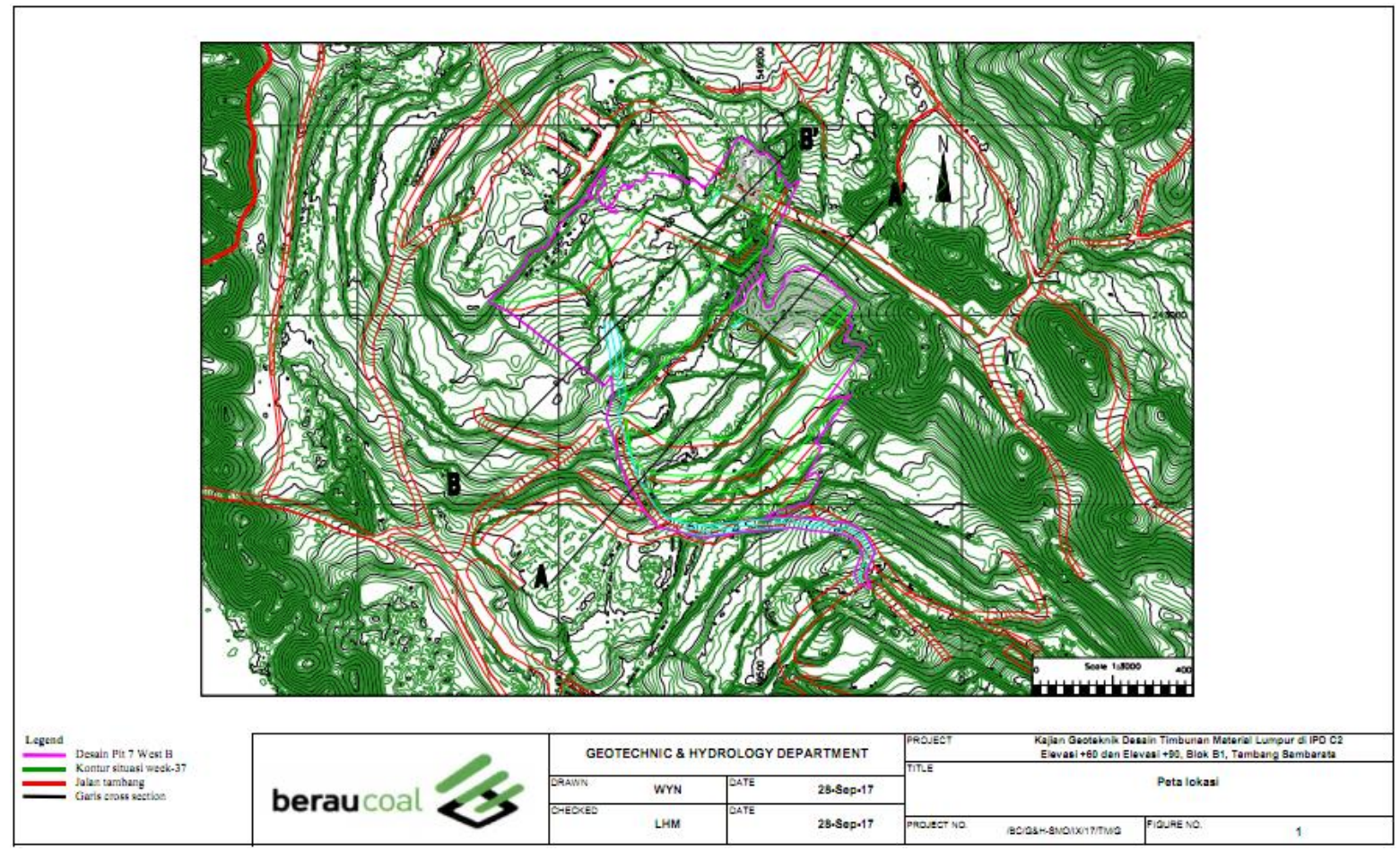

Gambar 1. Desain Timbunan Material Lumpur Pit C2

\section{A.3. Tujuan}

Tujuan yang diharapkan dari penelitian ini adalah untuk memberikan metode alternatif dalam aktifitas pengangkutan material lumpur cair khususnya pada proses penimbunannya di area disposal serta mengurangi resiko terjadinya kecelakaan tambang di area disposal lumpur.

\section{B. METODOLOGI PENELITIAN}

Keberadaan material lumpur di disposal akan memberikan pengaruh yang besar terhadap ketidakstabilan lereng disposal. Setiap disposal yang akan digunakan harus memiliki kestabilan lereng dengan faktor keamanan > 1,3. Pengambilan data lapangan dilakukan seperti data elevasi area, data 
pola air, data curah hujan, dan data lain yang mendukung dalam analisis geoteknik dan operasional penambangan. Pengambilan data ini sebagai dasar untuk melakukan analisis dalam penelitian ini.

Tabel 1 Properties Material

\begin{tabular}{|c|c|c|c|}
\hline \multirow[b]{2}{*}{ Material } & \multicolumn{3}{|c|}{ Parameter } \\
\hline & $\begin{array}{l}\text { Unit weight } \\
\left(\mathrm{kN} / \mathrm{m}^{3}\right)\end{array}$ & $\begin{array}{c}\text { Cohesion } \\
\left(\mathrm{kN} / \mathrm{m}^{2}\right)\end{array}$ & Phi $\left(^{0}\right)$ \\
\hline Bedrock & 20 & 175 & 21,5 \\
\hline Mudsump & 16 & 30 & 5 \\
\hline Existing fill 1 & 19,5 & 65 & 20 \\
\hline Existing fill 2 & 18,5 & 60 & 18,5 \\
\hline Existing fill 3 & 18,5 & 58 & 18,5 \\
\hline New fill & 18,5 & 55 & 18 \\
\hline
\end{tabular}

\section{HASIL DAN PEMBAHASAN}

\section{C.1. Geometri Sliding Pad}

Geometri pada area disposal lumpur cair terdapat bagian tanggul dan sliding pad. Tanggul pada area tersebut dibagi menjadi dua, yaitu tanggul pada bagian crest disposal dan tanggul pada bagian crest sliding pad. Kedua tanggul ini berfungsi sebagai pengendalian terhadap resiko unit hauler melewati crest lereng karena faktor tertentu seperti kelelahan (fatigue), skill operator, dan lain lain. Dimensi tanggul pada crest disposal berbeda dengan dimensi tanggul crest sliding pad. Pada tanggul crest disposal, tinggi tanggul sebesar 3/4 tinggi ban unit hauler terbesar yang bekerja pada area tersebut. Sedangkan untuk tanggul crest sliding pad sebesar $1 / 2$ tinggi ban unit hauler terbesar yang bekerja pada area tersebut. Hal ini bertujuan agar saat unit hauler mengangkat vessel untuk menumpahkan material, vessel unit hauler tersebut tidak tersangkut tanggul.

Pada area sliding pad, sudut yang dibentuk lebih kecil dari sudut crest disposal. Besarnya sudut sliding pad bergantung pada kekentalan atau karakteristik material lumpur yang diangkut. Pada penelitian ini sudut yang digunakan sebesar $20^{\circ}$ karena dianggap efektif untuk pergerakan material lumpur cair. Selain itu, pada sudut $20^{\circ}$ akan membentuk front disposal sebesar $11 \mathrm{~m}$, dimana lebar tersebut dapat menjadi jarak aman untuk unit hauler melakukan penimbunan dari crest disposal.

\section{C.2. Tahapan Penimbunan Material Lumpur}

Secara garis besar penimbunan material lumpur terdapat 5 tahapan sesuai dengan Gambar 3. Pada proses penimbunan ini, posisi unit hauler sejajar dengan crest disposal. Unit dozer hanya sebatas melakukan maintenance sliding pad, sehingga pergerakan material lumpur utamanya hanya dengan gaya gravitasi yang ada. Pos pengawas penimbunan diletakkan di sisi yang berlainan dengan front penimbunan sliding pad. 


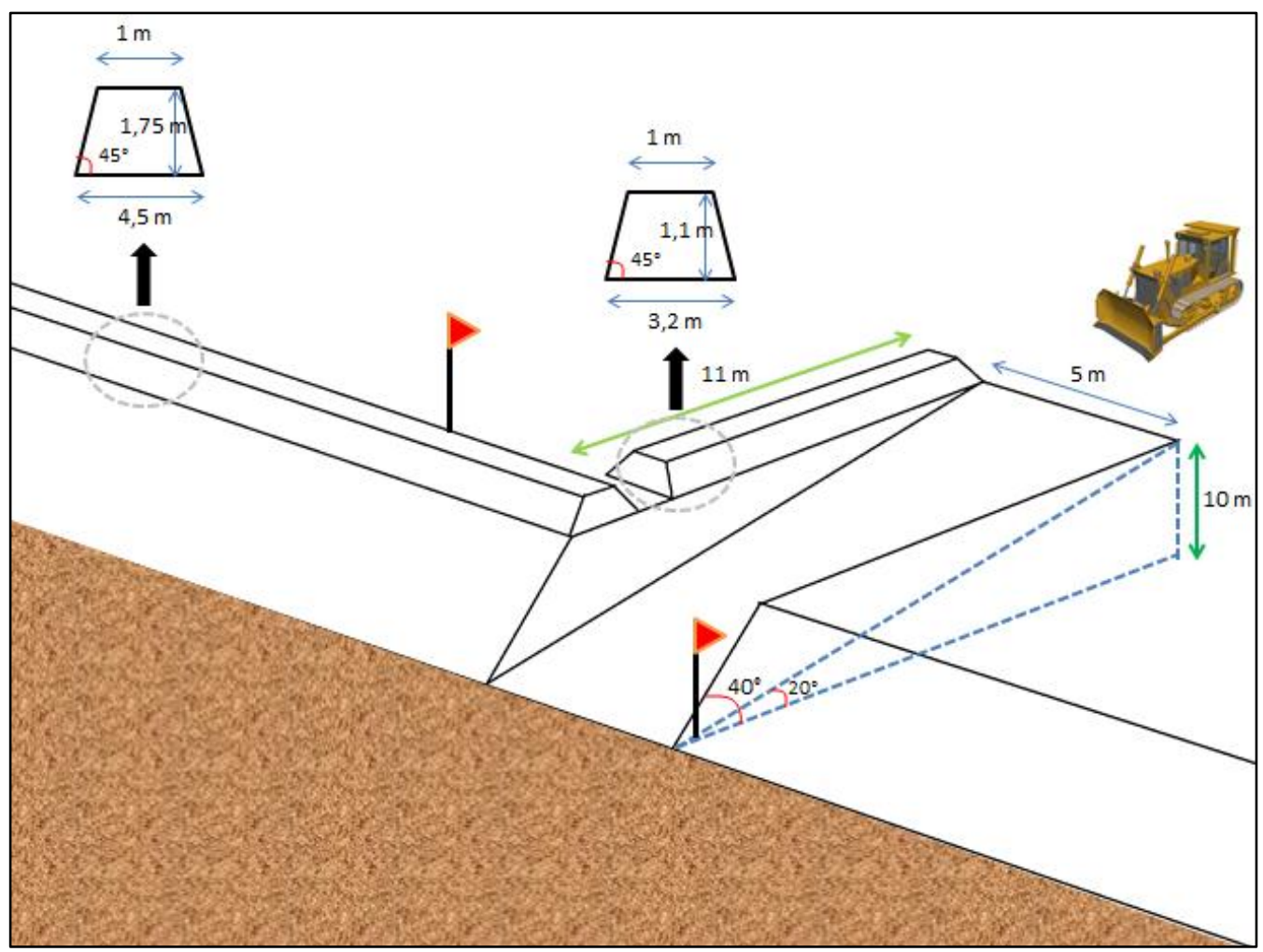

Gambar 2. Geomteri Sliding Pad

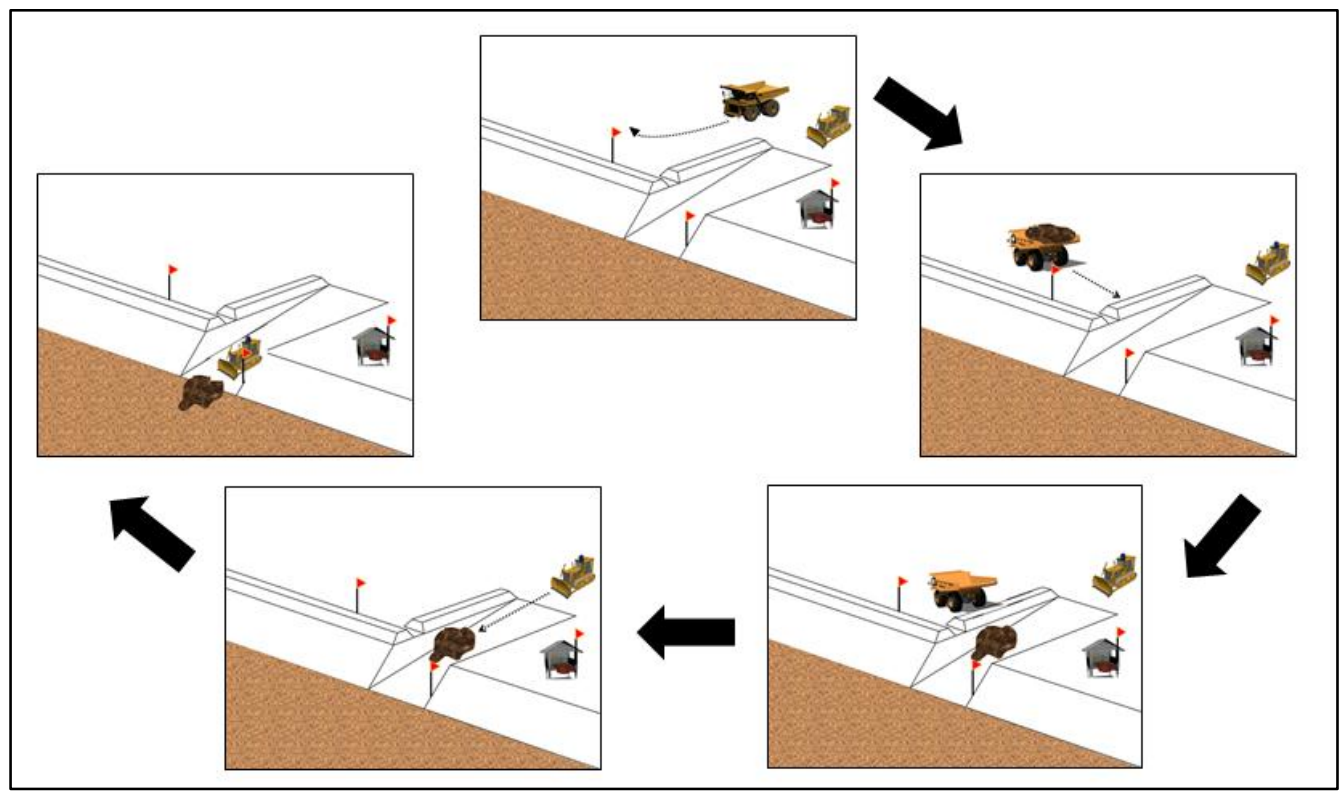

Gambar 3. Proses Penimbunan Material Lumpur 


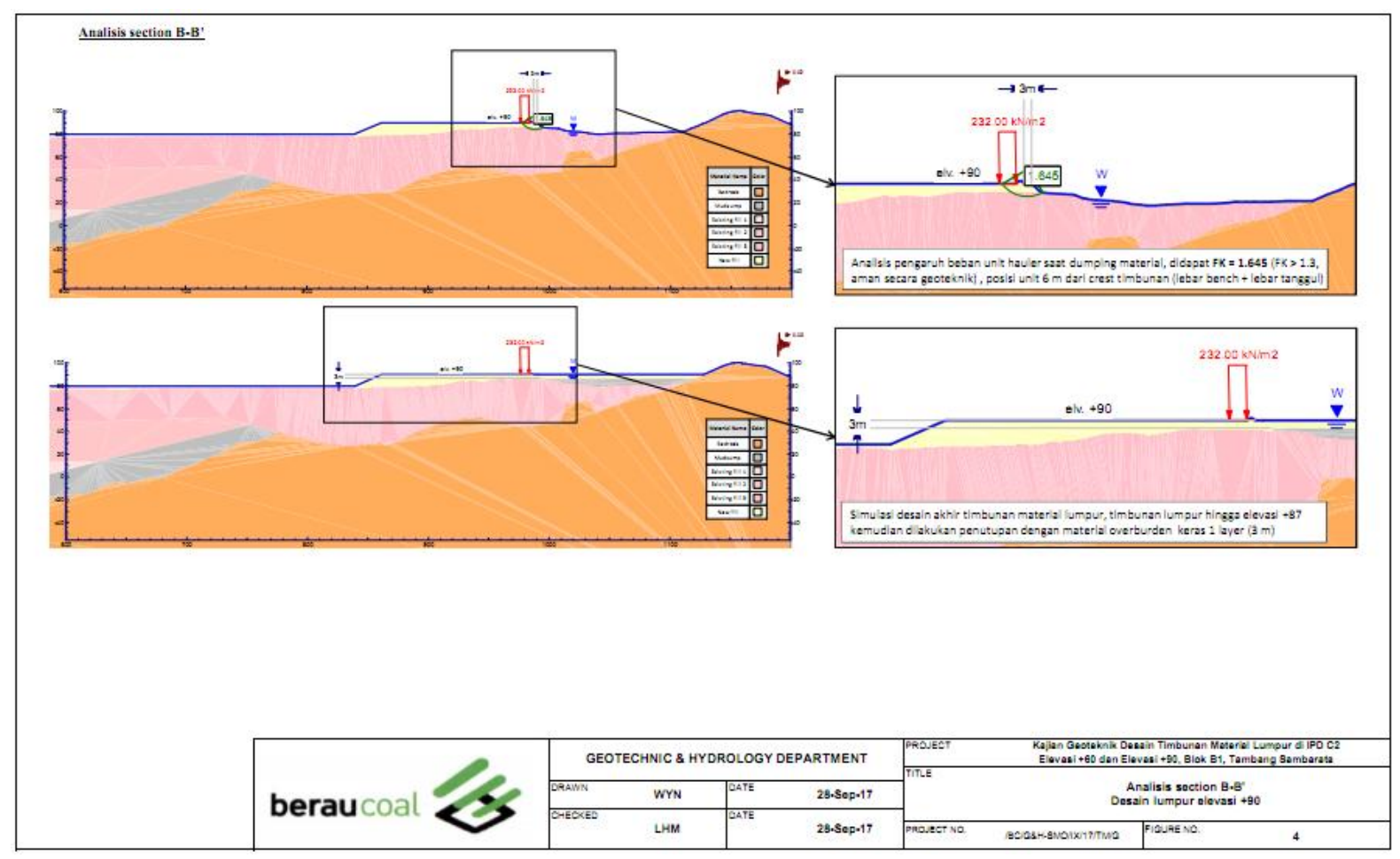

Gambar 4. Material Penyusun Disposal Lumpur

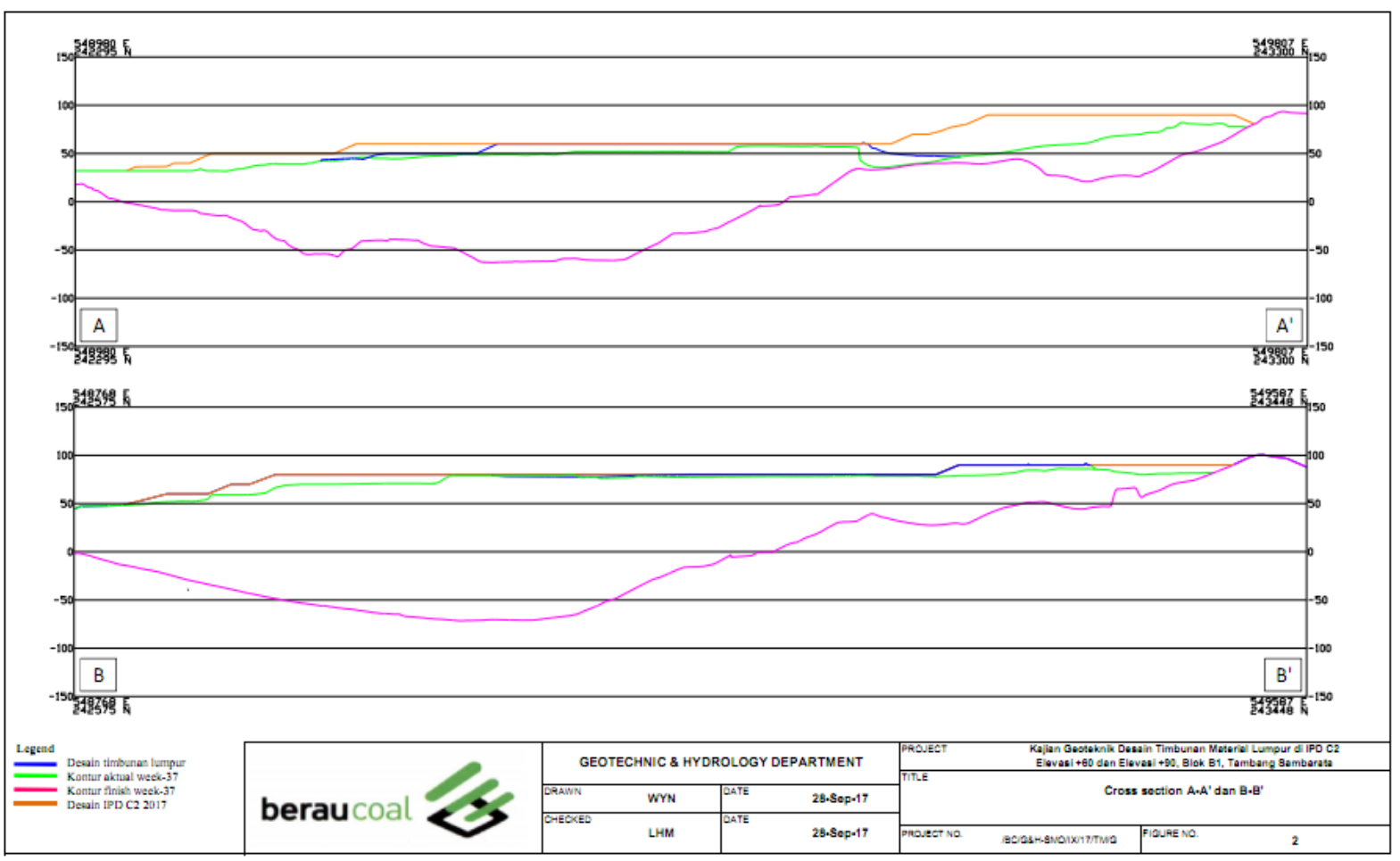

Gambar 5. Section Desain Disposal Lumpur 


\section{C.3. Analisa Geoteknik}

Analisis kestabilan lereng secara geoteknik dilakukan dengan beberapa pendekatan seperti data aktual kontur pada area IPD C2 dan data historikal material yang pernah ditimbun pada area tersebut. Metode yang digunakan dalam analisis ini adalah metode kesetimbangan batas. Tipe runtuhan circular dengan kondisi lereng diasumsikan homogeny fully saturated.

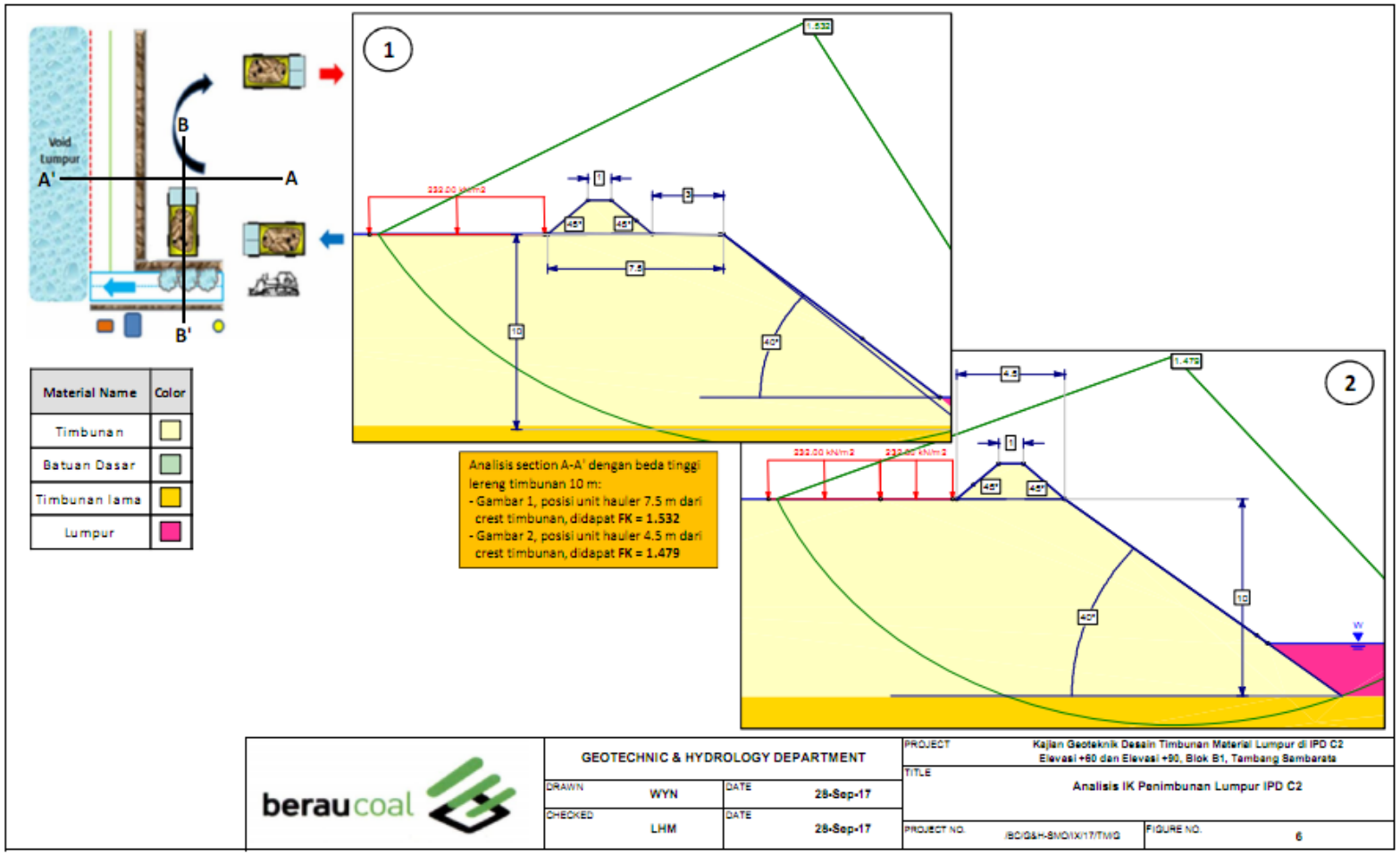

Gambar 6. Analisis Geoteknik Front Disposal

Secara desain untuk penimbunan material lumpur pada elevasi +90 dapat dilakukan. Analisis pengaruh beban unit hauler saat dumping material lumpur terhadap lereng timbunan, didapat $\mathrm{FK}=1.645$ (FK > 1.3, aman secara geoteknik), posisi unit $6 \mathrm{~m}$ dari crest timbunan (lebar bench - lebar tanggul). Desain akhir material lumpur ditutup dengan material overburden keras satu layer (tebal $3 \mathrm{~m}$ ). elevasi +90 merupakan elevasi teratas pada area sisi timur IPD C2 dan material lumpur ditempatkan pada area bekas jalan low wall dan perbukitan dengan di blok di sisi selatan menggunakan timbunan material overburden.

\section{KESIMPULAN}

Penggunaan Sliding Pad dalam penimbunan material lumpur di area disposal dapat diaplikasikan dan memiliki dampak yang signifikan, yaitu antara lain:

1. Mengurangi resiko terjatuhnya unit hauler dari crest disposal karena ketidakstabilan lereng atau terperosok dari crest

2. Meminimalkan beban kerja unit dozer untuk medorong material ataupun melakukan maintenance front disposal

3. Mengurangi perbaikan front disposal karena lumpur yang tercecer 


\section{DAFTAR PUSTAKA}

PT Berau Coal, 2017. Berau Coal Green Mining Systems Prosedur Penimbunan di Area Disposal, Tanjung Redeb: PT Berau Coal.

PT Berau Coal, 2017. Technical Memorandum Kajian Geoteknik Desain Timbunan Material Lumpur di IPD C2 Elevasi +60 dan Elevasi +90 Blok B1 Tambang Sambarata, Sambarta: PT Berau Coal 